\title{
A PRODUÇÃO DE MANUAIS DIDÁTICOS E O ENSINO DE SOCIOLOGIA NA ESCOLA MÉDIA EM DOIS MOMENTOS HISTÓRICOS (1935-1989)
}

\author{
Silvia Helena Andrade de Brito \\ PPGEducação e DCH/CCHS/UFMS \\ shbrito@terra.com.br
}

\section{RESUMO:}

O objeto desse texto são dois manuais dedicados ao ensino de Sociologia na escola média: o primeiro, produzido nos anos 1930, é Princípios de Sociologia, de Fernando de Azevedo; o segundo, dos anos 1980, é o texto Sociologia, de Paulo Meksenas. O objetivo desse trabalho é desvelar o conteúdo e proposta de utilização dos dois manuais analisados, considerando os distintos momentos da sociedade capitalista em que essas obras foram produzidas. Para a descrição do conteúdo e das metodologias de ensino optou-se pelo exame da apresentação, nos manuais, dos clássicos da Sociologia - Karl Marx, Émile Durkheim e Max Weber. Como conclusão, a análise das obras permite perceber como o manual vai se transformando no elemento direcionador do trabalho didático e como seus conteúdos são simplificados. Em função dessa perspectiva, as duas propostas dedicam parte de seus esforços a esclarecer como melhor utilizar o manual didático. Azevedo, ainda num momento de transição, discorre como seu texto poderia servir de guia ao trabalho de um professor cuja erudição seria importante na relação educativa. Já Meksenas, colocado no redemoinho do império do manual didático, não se furta a tratar pormenorizadamente das tarefas a serem desenvolvidas pelo professor, tendo como guia o manual didático.

Palavras-chave: manuais didáticos; ensino de Sociologia; Fernando de Azevedo; Paulo Meksenas

\section{THE PRODUCTION OF TEACHING MANUALS AND THE TEACHING OD SOCIOLOGY IN MIDDLE SCHOOLS AT TWO HISTORICAL MOMENTS [1935- 1989]}

\begin{abstract}
:
The objects of this text are two manuals dedicated to the teaching of Sociology in middle schools: the first, produced in the 1930s, Principles of Sociology, by Fernando de Azevedo; the second, in the 1980s, the text, Sociology, by Paulo Meksenas. The objective of this study is to reveal the content and proposals of usage of the two manuals that were studied, considering the distinct moments of capitalist society in which they were produced. The choice of the description of the content and teaching methodologies was made opting for the examination of the presentation, in the manuals, of the classics of Sociology - Karl Marx, Émile Durkheim and Max Weber. In conclusion, the works studied permitted perception of how the manual was transformed into a directive element of didactical work and how its contents are simplified. In function of this, the two proposals dedicated part of their efforts to clarifying how best to use the teaching manual. Azevedo, still in a transition period, discourses on how his text could serve as a guide to the teacher's work whose erudition sould be important to the educational relationship. Meksenas, for his part, placed the imperial swirl of the teaching manual, does not avoid detailed treatment of the tasks to be developed by the teacher, having for his guide, the teaching manual.

Keywords: Teaching manuals; teaching of Sociology; Fernando de Azevedo; Paulo Meksenas
\end{abstract}


Centrado na explicitação do lugar ocupado pelo manual didático na organização do trabalho desenvolvido na escola moderna, sobretudo considerando o caso brasileiro, o presente artigo é dedicado a análise de dois manuais voltados ao ensino de Sociologia na escola média1, tendo em vista seu desenvolvimento como disciplina, em dois momentos históricos: o primeiro, nos anos 1930, algum tempo após sua introdução no currículo do Colégio de Pedro II e das escolas normais, o que se deu em 1926 e 1928, respectivamente; o segundo, nos anos 1980, quando seu ensino estava vinculado aos cursos de magistério (formação de professores em nível de $2^{\circ}$ grau) e à escola de $2^{\circ}$ grau, na condição de disciplina optativa. Para o primeiro momento, a obra examinada é Princípios de Sociologia, de Fernando de Azevedo; e para o segundo momento, é considerado o texto Sociologia, de Paulo Meksenas.

São três os objetivos desse trabalho. Primeiramente, em termos gerais, pretende-se desvelar o conteúdo e proposta de utilização desse instrumento do trabalho didático, conforme descrito e sugerido pelos autores. Como objetivos específicos, propõe-se: 1. destacar as similaridades e distinções entre a proposta comeniana de uso do manual didático, visto ter sido Comenius o propositor primeiro da realização do trabalho didático centrado na utilização do manual didático, e o proposto pelos autores (o que foi incorporado/superado, historicamente); 2. destacar as similaridades/distinções entre as propostas dos próprios autores, considerando o que foi incorporado/superado por Azevedo e Meksenas, diante do processo de expansão/universalização da escola pública, nos distintos momentos históricos da história da educação no Brasil vividos por esses autores.

Para alcançar os objetivos propostos, um primeiro passo foi o levantamento secundário que permitiu conhecer as condições de produção de cada uma das obras, bem como traçar, em linhas gerais, o processo de institucionalização do ensino de Sociologia, em sua trajetória histórica. Esse levantamento também foi importante para a reflexão em torno das categorias que norteiam as análises realizadas neste texto, quais sejam, trabalho, trabalho didático, organização do trabalho didático, instrumentos do trabalho didático e manual didático. Em seguida, para a descrição do conteúdo e das metodologias de ensino de Sociologia propostas pelos autores, optou-se pelo exame de um tema, visto não ser possível abordar com profundidade o conjunto dos conteúdos ali expostos. O tema escolhido foi a apresentação, nos dois livros, dos clássicos da Sociologia - Karl Marx, Émile Durkheim e Max Weber. O estudo comparativo dos dois posicionamentos far-se-á por sua contraposição à proposta comeniana, por um lado; e pela contraposição dos autores entre si, considerada a particularidade existente em cada um dos momentos históricos no qual produziram.

O texto está dividido em quatro partes, a saber: 1. a descrição das condições de produção, do conteúdo e das metodologias de ensino de Sociologia propostas por Fernando de Azevedo, a partir do exame do tema escolhido - os clássicos da Sociologia - Durkheim, Marx e Weber; 2. a descrição das condições de produção, do conteúdo e das metodologias de ensino de Sociologia propostas por Paulo Meksenas, a partir do exame do tema escolhido - os clássicos da Sociologia - Durkheim, Marx e Weber; 3. a contraposição entre o proposto pelos autores e o método comeniano e contraposição entre o proposto pelos autores entre si, vistos como expressões de etapas distintas da história do ensino de Sociologia no Brasil; 4. considerações finais.

\section{0 manual didático proposto por Fernando de Azevedo}

Ao se tratar da disciplina Sociologia, é importante destacar que seu processo de institucionalização no Brasil enquanto campo científico ocorreu paralelamente ao seu 
processo de escolarização, nos distintos contextos em que isso se deu, entre o final do século XIX e a primeira metade do século XX. Nesse momento de surgimento da Sociologia como disciplina escolar destaca-se:

- em primeiro lugar, a tentativa de sua introdução por meio da Reforma Benjamin Constant, de 1891, que não se efetivou;

- num segundo momento, apareceram os compêndios de Sociologia Criminal, voltados aos estudantes de Direito (década de 1920);

- e, finalmente, ocorreu o seu definitivo aparecimento e implantação no currículo do Colégio de Pedro II, em outras escolas secundárias e no ensino normal, também nos meados dos anos 1920 e, entre 1931 e 19412, com a Reforma Francisco Campos, tornou-se disciplina obrigatória do curso complementar (MEUCCI, 2000).

Desta forma, o estreitamento das relações entre a Sociologia e a escola secundária e normal teve como consequiência uma produção significativa de livros voltados para o ensino da disciplina, segundo Meucci (2000), concentrada, sobretudo, entre os anos 1930 e 1950. A fonte desta produção era dupla: a primeira, formada por intelectuais que, saídos das lides educacionais enveredaram pelas searas da Sociologia (AZEVEDO, 1954; 1973; CARNEIRO LEÃO, 1958). A segunda, agrupando aqueles que, formados em Ciências Sociais e ou áreas afins, tomaram a educação como foco de suas preocupações (FERNANDES, 1980; CANDIDO, 1949; 2006; COSTA EDUARDO, 1949; COSTA PINTO, 1949; PIERSON, 1949; PEREIRA, 1967). Esses também acabaram produzindo reflexões sobre a penetração da disciplina na escola no Brasil, sobretudo entre os anos 1930 e 1950.

Meucci (2000) destaca, entre essas obras, os manuais didáticos dirigidos às escolas secundária e normal. Esses manuais, ao discutir os programas desenvolvidos nas escolas e ao tratar das recomendações pedagógicas que acompanhariam seu ensino, acabam levantando questões importantes quanto à organização do trabalho didático para a disciplina Sociologia no período3. Desse conjunto produzido entre 1930 e 1940, foi escolhida para análise uma das obras de Fernando de Azevedo, um dos principais responsáveis pela introdução e divulgação da Sociologia no Brasil.

Princípios de Sociologia, de Fernando de Azevedo, obra publicada pela primeira vez em 1935, era destinada ao ensino superior e ao ensino secundário e normal4. O objetivo da obra, na visão ao autor, prende-se àquela própria de qualquer manual científico5, isto é, “(...) iniciar e orientar os estudantes nessa nova ciência e fornecer aos professores uma fonte segura de informações". Frisa ainda que os manuais representam o fruto de um trabalho de síntese, e assim “(...) representam, na vida profissional, o coroamento de longos trabalhos de pesquisa, análise, crítica e reconstrução, pacientemente vividos, ordenados e sistematizados" (AZEVEDO, 1973, p. 1).

Considerado o caráter ordenado e sistematizado como inerentes ao manual científico, a obra de Azevedo inicia-se apresentando o que é a sociedade vista a partir do posicionamento da Sociologia ou, em outras palavras, o que são os fatos sociais, ponto de partido dos estudos sociológicos e, por isso, ponto de partida também do ensino de Sociologia. Desta forma,

Vendo e observando de perto os fatos, abraçando o maior número possível de realidades precisas e raciocinando sobre essas realidades, os alunos saberão o que é um "fato social", como se pesquisa, se observa e se controla, por terem eles mesmos pesquisado, observado e controlado, e se habituarão a estudar, dessa posição objetiva, não só as realidades do meio em que vivem, mas tudo o que se oferece ao seu exame, as fórmulas e as doutrinas. (AZEVEDO, 1973, p. 4) 
Dois aspectos podem ser aqui destacados: o que o autor entende por sociedade vai ao encontro de seu próprio posicionamento teórico-metodológico, tendo por referencial o funcionalismo francês, sobretudo Émile Durkheim. O segundo aspecto prende-se à perspectiva dos métodos ativos, que preconizavam a necessidade de que o aluno experimentasse, em situações concretas de aprendizagem, aquilo que era o objeto de cada ciência. Nesse caso, a própria vida social6. Assim, o autor advoga a experiência do fazer Sociologia como aspecto essencial do processo ensino-aprendizagem, desde já entendida a Sociologia como a ciência positiva, responsável pelo estudo dos fatos sociais.

O contato com o real, lembrando que "(...) a quantidade do saber é proporcional à quantidade de concreto, de real que lhe serve de base" (AZEVEDO, 1973, p. 5), faz-se pelo acesso aos documentos e pela crítica histórica, por um lado, e pelo trabalho de campo e a pesquisa social, por outro7. Papel fundamental cabe ao professor nesse processo, visto que os alunos são induzidos a ver e observar, visto que o pesquisador ou experimentador, papéis atribuídos pelo autor ao cientista social, é produto de um processo marcado por "(...) constante esforço de atenção, (...) um trabalho duro de espírito e uma disciplina rigorosa de estudos" (IDEM), iniciação que só o professor pode e deve dar.

Vencida essa etapa, que corresponde à primeira parte do livro (Os fatos sociais: os grupos, as formas, as atividades e a evolução social), Azevedo procura atingir aquilo que destaca como as características próprias a um bom manual científico, visto que ele não se destina apenas a alunos mas a professores e discentes. Nesse sentido, essa obra deve ser exata. Por exatidão o autor8 compreende a apresentação da história de constituição de um estudo científico que tem por objeto os fatos sociais, ou seja, a história da Sociologia. Isso inclui todas as teorias científicas, antigas e modernas, que marcaram e marcam o escopo teórico da disciplina, consideradas não a partir de seus distintos posicionamentos mas em função da contribuição que deixaram e deixam para a observação e explicação dos fatos sociais. Essa questão acompanha as quatro partes seguintes da obra, a saber: parte 2, denominada A penetração do espírito científico no estudo dos fatos sociais, abrangendo a história da Sociologia desde as primeiras tentativas de estudo da sociedade, a sua expressão ainda como Filosofia Social, ao seu aparecimento enquanto "ciência particular do social", iniciada com Auguste Comte, no século XIX e atingindo um caráter sistemático com Émile Durkheim; parte 3, denominada A ciência social, abrangendo a história da constituição de uma ciência sociológica no período que se seguiu a Durkheim9; partes 4 e 5, denominadas As escolas sociológicas do ponto de vista do método e As escolas do ponto de vista da explicação dos fatos sociais, respectivamente, abrangendo os métodos e os resultados das investigações sociológicas, consideradas as mesmas teorias trabalhadas nas partes 2 e 3 da obra.

Como o manual, embora tenha a ciência como sua base referencial (e por isso é denominado pelo autor de científico) cumpre simultaneamente função de aplicação didática, sua segunda característica é apresentar apenas a essência das diversas teorias sociológicas, o que é fundamental, deixando para segundo plano o que não se constitui como parte dos fundamentos de cada teoria exposta. Por essência das teorias científicas o autor destaca "as hipóteses científicas, as hipóteses de trabalho e as verdades apuradas" de cada constructo teórico, tendo como horizonte último o que contribuiu para tornar a Sociologia uma "ciência positiva, com objeto próprio" (AZEVEDO, 1973, p. 3).

A partir desses pressupostos Azevedo discute a metodologia de ensino a ser aplicada aos estudos sociológicos, partindo da tese de que o professor é peça-chave no processo ensino-aprendizagem, indispensável para que o aluno chegue à crítica, coordenação e sistematização do conhecimento. Não dispensa, nesses termos, nem a aula 
teórica, embora sugira que sua importância e exclusividade devam ser relativizadas pelo emprego do seminário, pela organização das pesquisas e pela participação em atividades como o clube de Sociologia ou o Museu Social. Sugere ainda a utilização de "(...) livros recentes e revistas científicas que permitam aos alunos seguir, nas suas linhas essenciais, as etapas sucessivas das grandes questões em curso de pesquisa, debate e verificação" (AZEVEDO, 1973, p. 7. Os grifos são nossos).

Ao mesmo tempo em que considera importante o professor do ensino secundário, sobretudo o de Sociologia, contribuir para a cultura geral de seus alunos - e nesse sentido não lhe cabe formar o sociólogo de profissão - considera também que sua tarefa não deva se respaldar na erudição mas no contato com os fatos. Limitada sua tarefa nessa perspectiva, o material a ser utilizado pelo professor pode se conformar no âmbito do manual científico que, em linhas gerais, pretende tão somente apresentar uma exposição completa, embora abreviada, do desenvolvimento e dos estudos sociológicos até então realizados.

Em relação aos clássicos da Sociologia, como dito anteriormente, Émile Durkheim e seus posicionamentos perpassam o conjunto do texto, visto que Fernando de Azevedo constrói sua visão sobre o que é a sociedade (leia-se, a capitalista) e sobre o que deva ser a Sociologia, como ciência positiva que visa estudar a sociedade (leia-se, o conjunto dos fatos sociais), fundamentado na perspectiva teórico-metodológica durkeiminiana. Embora veja seu estudo como imparcial e, dessa forma, objetivo, não deixa de enquadrá-lo como funcionalista.

Frente a isso, Durkheim e sua produção aparecem com destaque em todas as cinco partes do texto como expressão daquilo que a Sociologia produziu de mais avançado, sendo assim parâmetro para se medir os produtos já alcançados pelas pesquisas nas diferentes áreas das ciências sociais. Além disso, a ele são dedicados dois capítulos em especial (o capítulo 4 da parte 4 e o capítulo 4 da parte 5), visando apresentar seu método para a pesquisa e análise da vida social, bem como a sua visão acerca da sociedade capitalista.

Karl Marx é considerado, simultaneamente, filósofo social e sociólogo economista. Para Azevedo, somente nessa última condição sua produção é significativa para a Sociologia. Em razão disso a análise de sua obra está circunscrita ao materialismo histórico, cuja questão principal é a determinação econômica da vida social. No mais, seus escritos são considerados extracientíficos e normativos, ao extrapolar a trilha aberta pela explicação restrita aos fatos sociais.

Visto dessa forma, o método marxista, que o autor relaciona ao veio filosófico de Marx, não é discutido na seção respectiva, bem como a literatura produzida pelo autor. Quando discutido, em apenas dois momentos do livro (capítulo 2, parte 2 e capítulo 3, parte 5), o marxismo aparece pelos textos de comentaristas como G. de Greef, E. Sée, A. D. R.-A. Seligman e E. Vandervelde (apud AZEVEDO, 1973, p. 265-266).

Já Max Weber faz jus a uma referência (a obra Economia e sociedade) mas é visto por Azevedo como parte da tradição contemporânea da Sociologia. Nesse sentido, é referido em dois momentos (capítulo 4 da parte 4 e capítulo 5 da parte 5), um dedicado a expor sua metodologia (a proposta de utilização metodológica dos tipos ideais) e outro a sintetizar os aspectos fundamentais de sua teoria, dentro do bloco dedicado aos sociólogos alemães contemporâneos.

\section{0 manual didático de Paulo Meksenas}

O outro manual escolhido para exame foi produzido na primeira metade dos anos 1980, momento em que reiniciaram as discussões e a mobilização em torno da volta da 
disciplina Sociologia ao currículo do ensino de $2^{\circ}$ grau10, após 16 anos de ditadura militar, quando permanecera apenas a Sociologia Educacional no curso de Magistério.

O livro de Paulo Meksenas, intitulado Sociologia11, resultou do projeto "Diretrizes Gerais para o Ensino de $2^{\circ}$ grau: Núcleo Comum e Habilitação Magistério", proposto e desenvolvido entre 1985 e 1988 pela Coordenadoria para Articulação com Estados e Municípios (COEM) da Secretaria do Ensino de $2^{\circ}$ Grau (SESG) do Ministério da Educação e Cultura (MEC). Em sua parte operacional contou com a participação da Pontifícia Universidade Católica de São Paulo, que coordenou o trabalho dos 28 professores especialistas que estiveram à frente da preparação dos livros para as disciplinas em questão, entre elas a Sociologia12.

Essa obra também é dedicada a professores e alunos, em qualquer curso do $2^{\circ}$ grau no qual conste a disciplina Sociologia, embora tenha surgido de uma iniciativa que tinha como foco os cursos de formação de professores. Nesse sentido, entre os objetivos gerais da Coleção estão, entre outros,

(...) assegurar um sólido domínio dos conteúdos como base para a formação científica e profissional e para a consciência crítica das tarefas sócio-políticas e pedagógicas do ensino; (...) favorecer o trabalho conjunto dos professores na escola de modo a assegurar, dentro de um projeto pedagógico unitário, a interdisciplinaridade e as peculiaridades de cada disciplina. (MEKSENAS, 1994, p. 7)

Para atender a esses objetivos, o livro está organizado em duas partes. Na primeira, denominada Questões ao professor, reúnem-se três capítulos, discutindo, em linhas gerais, a proposta metodológica para a utilização, pelo professor, do livro em questão. Inicia-se apresentando a disciplina Sociologia, em sua trajetória tanto como campo do saber científico como enquanto disciplina escolar. Os capítulos 2 e 3, por sua vez, dedicam-se a expor o conteúdo a ser trabalhado em sala de aula, acompanhado das propostas de metodologia de ensino a serem utilizadas pelo professor.

$\mathrm{Na}$ segunda parte ( $O$ curso de sociologia: alunos e professores) são reunidos os quatro capítulos dedicados às unidade temáticas propostas para o desenvolvimento do conteúdo da disciplina, a saber: a) capítulo 4 - humanização da natureza; b) capítulo 5 sociedade capitalista; c) capítulo 6 - Estado e movimentos sociais e d) capítulo 7 - Família e escola. A estrutura dessas unidades segue uma articulação pré-determinada pelo autor, que inclui quatro componentes: a seleção de textos, incluindo um conjunto de excertos considerados significativos para a discussão das temáticas envolvidas em cada unidade; a orientação de estudos, traçando, em linhas gerais, os objetivos a serem alcançados, as categorias a serem dominadas e o conteúdo a ser abordado naquela unidade em questão; as sugestões didáticas, conjunto de propostas relacionadas à metodologia de ensino das Ciências Sociais para a escola de $2^{\circ}$ grau, detalhando técnicas de ensino a serem empregadas pelo professor, número de aulas dirigidas a cada elemento da unidade temática, entre outros; a indicação de leitura complementar, abrangendo o conjunto de obras que poderiam enriquecer os conteúdos desenvolvidos naquela unidade em estudo.

Entre as questões de cunho metodológico, é importante ressaltar duas observações de Meksenas (1994, p. 11). A primeira em relação aos conteúdos: o autor esclarece que se tornou necessário realizar uma seleção, sendo a escolha de “(...) conhecimentos socialmente importantes para a construção da cidadania do leitor" o critério que presidiu a organização das unidades temáticas no interior do livro. Detalhando melhor esse critério para a seleção dos conteúdos, assim declara o autor: 
a) Definimos preliminarmente um conteúdo sociológico crítico como aquele que possibilite entender a totalidade social não como um fenômeno único, e sim como um fenômeno contraditório.

b) Um conteúdo que se paute pelo princípio da contradição, no qual a dinâmica da sociedade é compreendida como resultado de relações sociais que, ao mesmo tempo, são complementares e também antagônicas. (...)

c) Só um conteúdo sociológico crítico contribuíra para que o indivíduo compreenda a dinâmica das relações sociais de modo que se perceba nelas como um elemento ativo - para, a partir daí, conceber sua cidadania como prática transformadora.

d) Um conteúdo sociológico pensado nesses termos pode ser útil no processo de conquista da cidadania, pois será capaz de mobilizar o indivíduo não só para uma reflexão "descomprometida" coma a realidade, mas para uma reflexão transformadora da realidade. (MEKSENAS, 1994, p. 16. Grifos do autor.)

Nesses termos, Meksenas estabelece o marxismo como fio condutor da análise que será feita sobre a sociedade contemporânea, visto ser essa a matriz teórico-metodológica capaz de embasar uma visão crítica sobre os processos sociais. Por isso as categorias que presidem a organização dos conteúdos desenvolvidos na obra são trabalho e conhecimento, que se desdobram nas quatro unidades temáticas do livro: inicia-se discutindo a importância do trabalho e do conhecimento na história das sociedades humanas (unidade 1); passa-se à reflexão em torno de como se manifestam trabalho e conhecimento na organização e dinâmica da sociedade capitalista (unidade 2); em seguida, o debate gira em torno das tramas sociais que, a partir do trabalho e do conhecimento constituem as relações de poder e da participação política do cidadão no contexto social (unidade 3); finalmente, como as mesmas categorias nucleares atravessam a constituição de outras instituições sociais, notadamente a escola e família (unidade 4).

Como é necessária a distribuição desse conteúdo por duas horas semanais de aula, considerando um ano de trabalho letivo, “(...) não tivemos a intenção de organizar um conteúdo que levasse o aluno a uma erudição em Sociologia, o que seria mesmo impraticável e indesejável nesta fase" (MEKSENAS, 1994, p. 25). Ressalva, contudo, que "ao aprender essas noções básicas, movido por interesse próprio, ele será capaz de prosseguir com estudos mais aprofundados em Sociologia."

Quanto à segunda observação, sobre a metodologia de ensino, o autor enfatiza que somente uma metodologia adequada para desenvolver no aluno o senso crítico - aquele que se funda na análise científica - é capaz de garantir o conhecimento adequado à constituição da cidadania. Para tal, considera essencial o movimento permanente de problematização e teorização como partes essenciais da metodologia de ensino da Sociologia. A problematização é entendida como o primeiro momento do processo de aprendizagem, e consiste em "(...) criar uma situação que desperte no aluno a necessidade de entender os fenômenos de seu cotidiano de uma outra perspectiva que não a de senso comum (IDEM, p. 27. Grifo do autor.). A teorização, por sua vez, consiste na reflexão rigorosa e sistemática sobre os processos indicados pelos alunos na problematização, por meio do arsenal científico disponibilizado pela Sociologia. São, dessa forma, momentos contraditórios mas complementares de um único movimento de análise da realidade social.

Particularmente em relação à problematização, o autor alerta para a importância de se ter claro que partir da realidade do aluno não significa afirmar que o conteúdo a ser desenvolvido em sala de aula deva se limitar ao que o aluno sabe. Corre-se o risco, com isso, de lidar apenas com o senso comum, quando a proposta é fornecer ao discente o 
instrumental científico necessário para que ele possa, inclusive, reelaborar o próprio conhecimento advindo do senso comum, reafirmando-o ou não.

Como decorrência do exposto no parágrafo anterior, Meksenas considera fundamental o papel a ser desempenhado pelo professor, na condição de orientador, organizador e transmissor do conhecimento teórico: "a tarefa primordial do professor é portanto relacionar o conhecimento de senso comum ao conhecimento científico, capacitado que está por uma carga maior de leituras, pelo acesso às regras de reflexão sistematizada etc" (MEKSENAS, 1994, p. 28). Ele é o responsável por organizar o processo de teorização, sendo a aula expositiva um dos momentos significativos desta fase do processo de ensino-aprendizagem. Isso significa que é função do professor não só preparar a aula como conduzir a passagem do aluno das noções de senso comum à incorporação dos domínios científicos, pressupondo, portanto, que esteja atualizado em relação à produção da área, em relação às discussões em torno do ensino de Sociologia e que seja, principalmente, capaz de produzir material didático (sínteses), com base nas discussões e literatura acessadas.

Além da aula expositiva, o autor recomenda o uso das dinâmicas de grupo como momentos importantes na problematização da experiência social dos alunos. Assim,

Se a exposição do professor pode garantir o desdobramento do conteúdo, a dinâmica de grupo ajuda no questionamento das concepções de senso comum, motivando e despertando o aluno para a importância de relacionar os fatos "isolados" do seu cotidiano com a totalidade social. (MEKSENAS, 1994, p. 29)

Entre as dinâmicas de grupo sugeridas pelo autor estão o debate motivado pela análise de fotos e desenhos, de textos (poesias, artigos de jornal, entre outros) e de recursos audiovisuais (músicas, por exemplo).

Fechando a discussão acerca da metodologia de ensino de Sociologia, o autor destaca a centralidade atribuída pela escola no Brasil ao livro didático. Sem se deter na reflexão sobre o papel do livro didático na escola, Meksenas ensaia uma proposta de ensino que considera alternativa em relação ao livro didático. Partindo do pressuposto de todo livro didático é permeado por uma certa visão do que seja a sociedade e como ela se organiza - tomando como universo o livro didático voltado para o ensino de Sociologia - o autor propõe que o professor tenha um distanciamento crítico desse instrumento de trabalho.

Como se garantiria essa condição, considerando a dificuldade de se abandonar o livro didático? Na medida em que não fosse utilizado com exclusividade um único livro didático, mas se levasse os alunos a ter contato com vários autores, levando-os a questionar a fundamentação teórica que se coloca como base para a visão de mundo de cada autor. Ou seja, a intenção é questionar o caráter linear a partir do qual o livro didático constrói seus pressupostos sobre a vida social, apresentando "(...) a visão de mundo de uma classe como a única possível” (MEKSENAS, 1994, p. 31). Dessa forma,

(...) concluímos afirmando que não é impossível associar a proposta de conteúdo apresentada nesse projeto com a utilização de livros didáticos. Essa é uma possibilidade que depende, como vimos, da maneira como são empregados. Depende do distanciamento crítico que se tenha do texto, na confundindo o conteúdo do curso com as informações do livro. Por último, depende do confronto da realidade apresentada no texto com aquela vivida pelo aluno. (MEKSENAS, 1994, p. 31-32) 
Complementando tal posicionamento, Meksenas atribui “(...) à linguagem direta com que o texto é apresentado" o motivo que levaria o leitor a ter "(...) a sensação de lidar com 'receitas', prontas para serem utilizadas" (MEKSENAS, 1994, p. 12). Esse aspecto fica evidenciado sobretudo quando se refere às sugestões didáticas que acompanham o desenvolvimento de cada uma das unidades temáticas. Exemplificando, o capítulo 5, que tem como eixo o estudo da sociedade capitalista, está subdividido em quatro grandes temas: a) a organização social capitalista na concepção funcionalista; b) a organização social capitalista na concepção histórico-crítica; c) o processo de controle social; d) sociedade capitalista: reprodução e resistência. Quais são as sugestões didáticas para o desenvolvimento desses temas?

Ao primeiro tema, centrado no estudo da teoria funcionalista de Émile Durkheim, o autor sugere que sejam dedicadas seis aulas, descrevendo em seguida o que o professor poderia desenvolver em cada umas delas. A título de exemplo, será transcrito o detalhamento da terceira aula:

Para a terceira aula, propõe-se uma nova problematização de conteúdo: um debate no qual o professor lança as seguintes questões: "Poderíamos afirmar que existem certas regras para a convivência em sociedade? Por quê [sic]? Quais seriam algumas dessas regras que a sociedade impõe? Pode-se admitir essas regras sociais como a moral de uma determinada sociedade? No que difere a moral da nossa sociedade urbano-industrial da moral de uma sociedade indígena?" (MEKSENAS, 1994, p. 97)

Em relação aos clássicos da Sociologia, a teoria de Karl Marx é o veio teórico no qual transita o autor, portanto, a visão de sociedade que o texto objetiva inculcar no aluno, e que precede a organização da obra, traz essa marca. O livro não conta, no entanto, com nenhum texto de Marx, afora um excerto da obra A origem da família, da propriedade privada e do Estado, de Engels, embora as obras $O$ capital e $A$ ideologia alemã apareçam na bibliografia final. $\mathrm{O}$ texto referente à teoria marxista, parte do capítulo 5 (A organização social capitalista na concepção histórico-crítica, p. 71-82), incluindo a vida e obra do autor, além dos principais conceitos do materialismo histórico (mercadoria, capital, lei da maisvalia, classes sociais, Estado e ideologia), são apresentados por meio de extratos produzidos pelo próprio autor, retirados de outros livros dedicados também ao ensino de Sociologia (ou Sociologia da Educação)13 (MEKSENAS, 1987; 1988; 1994).

A mesma proposta orienta a apresentação da obra de Émile Durkheim, cuja teoria é sugerida como a contraposição à visão marxista de homem, ciência e sociedade. Considerando que o autor baseia a construção de seu texto na categoria trabalho, entendido como “(...) o elemento organizador da vida social, pois é a única atividade que permite ao ser humano desenvolver uma ação-reflexão sobre a natureza a ponto de transformá-la segundo suas necessidades" (MEKSENAS, 1994, p. 23), elabora o quinto capítulo de seu manual pela contraposição das duas concepções de mundo que permeiam as relações de trabalho na sociedade capitalista, a saber: item 1 A organização social na concepção funcionalista, representando os interesses da classe dominante, voltada à perspectiva de conservação da sociedade capitalista; item 2 A organização social na concepção históricocrítica, representando os interesses da classe trabalhadora, voltada à perspectiva de transformação da sociedade capitalista. Dada a perspectiva do autor de que o foco da obra não deve ser a “(...) erudição em Sociologia”, e que esse princípio foi central na delimitação dos conteúdos propostos para estudo, não aparece no texto menções à teoria de Max Weber. 


\section{A proposta comeniana de manual didático e suas interfaces com as obras de Fernando de Azevedo e Paulo Meksenas}

Assim, a partir das informações apresentadas, esse trabalho apresenta a proposta de pensar o manual didático como instrumento de trabalho nos ensinos secundário e normal, evidenciando seu caráter histórico e questionando sua naturalização como coisa que esteve sempre presente dentro das escolas, independentemente das transformações sofridas pela sociedade. Nesses termos é essencial reconstruir, historicamente, as diferentes funções assumidas pelos instrumentos de trabalho, visto que essas funções são determinantes para se compreender o conteúdo e os usos que se fizeram dos mesmos. Em outras palavras, problematizar conteúdos e usos dos instrumentos do trabalho didático é opor-se a pensá-los como se eles sempre tivessem estado ali, naquele espaço eterno, desempenhando a mesma imemorial função. Isso se impõe mesmo nos casos em que o instrumento do trabalho didático se nos apresenta como um "velho" conhecido, como é o caso do manual didático.

Esse último, desde a proposta pioneira de Comenius para sua utilização, no século XVII, visando "ensinar tudo a todos" (ALVES, 2001; 2005), vem sofrendo mudanças, no seu uso e conteúdos, determinadas pelas transformações impostas à educação, no interior da sociedade capitalista. Em função disso torna-se necessário compreender como se construiu, o que Alves denomina de "(...) império do manual didático no espaço escolar" (2005, p. 70), buscando na história as raízes desse processo. Também será no exame do processo histórico de constituição da escola moderna no Brasil que se encontrarão respostas para problemas relativos às diferenças entre formas assumidas por esse instrumento de trabalho no período em estudo, evidenciando a diferença entre o proposto por Fernando de Azevedo, nos anos 1930/1940, e o trabalho de Paulo Meksenas, na década de 1980.

No caso desse trabalho, a obra de Fernando de Azevedo situa-se no período compreendido entre os anos 30 do século XIX e a primeira metade do século XX, momento que precedeu a universalização da escola pública no país, e que implicou em transformações na organização do ensino e de seus instrumentos de trabalho. É nesse segundo período histórico, quando a expansão da escola básica fortaleceu a implantação de uma indústria gráfica voltada para a produção de manuais didáticos14, entre outros processos que permitiram materializar a "escola para todos", que apareceu o segundo manual aqui analisado, a obra de Paulo Meksenas.

A proposta de utilização do manual didático na escola moderna, contudo, não é recente. Em função disso, para se tratar adequadamente desse instrumento do trabalho didático a análise deve partir da preocupação em mostrar os instrumentos do trabalho como elementos centrais para revelar a natureza histórica da relação educativa. Para tal, serão referidos aqui os resultados de duas pesquisas que se aprofundaram no estudo do trabalho didático (ALVES, 2001; 2005). A primeira discutiu a origem e o desenvolvimento da escola moderna. Demonstrou, em especial, o fato de a organização do trabalho didático dominante nas escolas de nosso tempo se reportar a Comenius e se expressar como uma forma de manifestação da organização técnica do trabalho manufatureiro (ALVES, 2001). A segunda tinha como objetivo fundamental evidenciar as diversas formas históricas de organização do trabalho didático, que se sucederam desde a emergência do ensino de caráter coletivo ainda na sociedade feudal, com o modus parisiensis de ensinar, em meados do século XVI, até o predomínio do ensino mútuo no século XIX. Foi no interior desse segundo trabalho que Alves começou por explicitar claramente a acepção conferida à expressão organização do trabalho didático: 
a) ela é, sempre, uma relação educativa que coloca, frente a frente, uma forma histórica de educador, de um lado, e uma forma histórica de educando(s), de outro;

b) realiza-se com a mediação de recursos didáticos, envolvendo os procedimentos técnico-pedagógicos do educador, as tecnologias educacionais e os conteúdos programados para servir ao processo de transmissão do conhecimento,

c) e implica um espaço físico com características peculiares, onde ocorre. (ALVES, 2005, p. 10-11. Grifos do autor.)

Quando se trata da relação educativa, portanto, ela está sendo entendida por sua estreita associação com uma forma de organização do trabalho didático. Na verdade, ela só pode ser historicizada quando referida à peculiar forma de organização do trabalho didático que lhe é pertinente. Além disso, não há organização do trabalho didático que se realize sem a mediação de determinados instrumentos de trabalho, elementos essenciais na constituição de uma dada relação educativa.

Nesse ponto, Alves enfatiza a necessidade se voltar a Comenius, justamente celebrado como o principal mentor da escola moderna, e à sua obra clássica, chave teórica para o entendimento da organização do trabalho didático que se tornou dominante na escola da sociedade capitalista (COMÉNIO, 1976). Nesse sentido, é necessário expressar um reconhecimento, logo de início. Premido pelas necessidades sociais de seu tempo, esse educador pensou uma instituição social que realizasse a função de "ensinar tudo a todos", como dito anteriormente. Essa primeira conclamação à universalização da educação escolar representava, de fato, a crítica à relação educativa então dominante, que supunha a presença de um preceptor em face de um discípulo. Tal relação, de caráter individual, elevava significativamente os custos dos serviços educacionais, pois o preceptor deveria ser um "artífice primoroso" e "dotado de conhecimentos invulgares" (ERASMO, 1996, p. 9; 26), isto é, um sábio cujo conhecimento elevava-se muito acima da média. Tal relação já não poderia se sustentar quando a pressão social clamava pela difusão da educação para todos, iniciativa cujo sucesso repousava, sobretudo, na possibilidade de barateamento dos serviços educacionais. Numa época em que as escolas existiam em número limitado; em que inexistiam educadores em número suficiente para enfrentar a imensa demanda gerada pela necessidade de universalização da educação; em que os recursos didáticos, como as obras clássicas, tinham difusão limitada, apesar da invenção da imprensa de caracteres móveis, Comenius pensou a instituição social que estava ajudando a criar a partir da divisão do trabalho. Essa idéia ele tomara das manufaturas, já em pleno processo de amadurecimento, que anunciavam uma nova época, de domínio da produção capitalista15. Daí a proposta de seriação das escolas, a divisão precisa dos níveis de ensino, a separação clara das áreas do conhecimento no plano de estudos e, até mesmo, a especialização dos instrumentos de trabalho, no caso, manuais didáticos, agora múltiplos, pois ajustados a cada nível de escolarização e a cada área do conhecimento16. Por essa via seriam barateados os custos da educação escolar, condição sine qua non da universalização do acesso.

O elemento que tornaria possível a realização dessa proposta manufatureira era, principalmente, esse instrumento de trabalho aperfeiçoado por Comenius, que passava a ser o elemento preponderante no trabalho didático, pois a ele caberia a função de garantir a transmissão do conhecimento. Visto dessa perspectiva, o manual didático, instrumento de trabalho por excelência dentro da escola moderna, portanto, não teve um surgimento casual e aleatório. Ele foi o recurso intencionalmente vislumbrado por Comenius para o exercício da função aventada. Assistia-se, assim, à emergência da supremacia do instrumento de 
trabalho no âmbito da educação escolar, à instauração do domínio da atividade do professor pelo manual didático. Aquele era relegado a uma posição subalterna na relação educativa, pois seus procedimentos pedagógicos passavam a ser ditados pelo próprio instrumento de trabalho (ALVES, 2001).

Fechando essa discussão, Alves enfatiza como pode surpreender a muitos o fato de o manual didático ter-se cristalizado e ganho uma longa sobrevida, mesmo em face da ocorrência da revolução industrial e da emergência de outros instrumentos de trabalho didático, visto ser uma tecnologia de caráter histórico, nascida como um recurso possível no século XVII, visando a atender necessidades educacionais de então. A escola do manual didático, contudo, continuou com as suas bases plantadas no século XVII e, por preservar a organização manufatureira do trabalho didático, esse se tornou cada vez mais presente na sala de aula. Nesse sentido, o manual didático, que pretendia oferecer uma síntese dos conhecimentos humanos, mais adequada ao trabalho do professor com crianças e jovens,

\begin{abstract}
Especializou-se, também, em função dos níveis de escolarização e das áreas de conhecimento, multiplicando-se da mesma forma que os instrumentos de trabalho, dentro da oficina, que, por força da divisão do trabalho, ganharam as configurações mais adequadas às operações que realizavam. Desde então, o manual didático passou a servir em tempo integral ao aluno e ao professor. Foram criadas, mesmo, modalidades especializadas de textos para aquele e para este, mas, rigorosamente, concebidas como elementos complementares. De imediato, importa reconhecer que o manual didático, pela sua auto-suficiência enquanto instrumento organizador do trabalho de ensino, dispensou da escola outros elementos, como o livro clássico." (ALVES, 2001, p. 86-87)
\end{abstract}

Caminhando num sentido que é concordante sobre o papel central do manual didático na relação educativa, vários autores que trataram da temática (MUNAKATA, 1998) (BITTENCOURT, 1997), (FONSECA, 1993), (DEIRÓ, 1981), (BONAZZI \& ECO, 1980), também demonstram que o manual didático é o elemento que orienta, transmite, organiza e informa todo o processo de ensino, "é a fonte exclusiva e definidora do ensino" (FONSECA, 1993). Fonseca trata, inclusive, da existência de uma ditadura do livro didático. Toda a discussão sobre a inserção ou "transposição" de variadas fontes, novas tecnologias e de novas linguagens no trabalho didático teria ficado no plano do discurso, ao longo da história de utilização do manual didático.

Com isso, o instrumental próprio do fazer científico não penetrou na escola. A forma de se fazer pesquisa em todos os campos do conhecimento, os métodos específicos de cada campo, não foram incorporados no trabalho didático. O império do manual, como foi denominado por Alves (2003), e a ditadura do manual, como foi diagnosticado por Fonseca (1993), impediram que se tivesse acesso ao saber científico, à cultura sistematizada, às fontes do conhecimento, à produção científica17.

Em termos de desafios postos à pesquisa em História da Educação, e na senda aberta por Fonseca e por outros autores que demonstraram a centralidade do manual didático; e, sobretudo por Alves, permanecem interrogações acerca das funções e do uso desse instrumento de trabalho, considerando a dialética entre o que permanece - sendo reproduzido ao longo da história da educação escolarizada - e aquilo que foi superado, reconfigurando o manual didático em cada etapa da história dessa sociedade. É nesse veio que o presente artigo pretende colaborar, analisando os manuais de Sociologia propostos por Azevedo e Meksenas, visando mais de perto a história da educação no Brasil. 
Como visto anteriormente, em termos históricos, Azevedo produziu Princípios de Sociologia quando ainda não havia se estabelecido o processo de expansão do ensino público no país, ou seja, a "escola para todos" ainda não se materializara. Sem ela, a necessidade do manual didático comeniano, pensado como instrumento de trabalho apropriado a essa fase da escola moderna, perde a sua principal razão de ser, torna-se desnecessário. Isso pode explicar porque o texto azevediano, embora produzido a partir de uma preocupação do autor em tornar o conhecimento sociológico acessível para discentes de diferentes graus de ensino, ainda é marcado por um viés erudito que já não se percebe no manual didático produzido por Meksenas. Esse último, trabalhando num período da escola moderna em que sua universalização é imperativa, não poderia mais produzir um instrumento de trabalho que se preocupasse com a erudição dos alunos, sendo essa tarefa adiada para momentos posteriores de sua formação. Contraditoriamente, contudo, os dois autores reconhecem que suas obras, mesmo sendo de caráter introdutório, sejam úteis para discentes do ensino superior, o que viria a estender para um momento ainda mais distante e difícil de ser alcançado - o trabalho de formação desse aluno.

O mesmo viés erudito de Azevedo, contudo, ao mesmo tempo que lhe permite e compromete com uma exposição o mais completa possível do que já fora produzido na Sociologia científica até aquele momento histórico - e por isso o volume se estende por alentadas 329 páginas — também o desobriga, já em pleno século XX, a se comprometer ou comprometer seus leitores com a leitura, por exemplo, dos clássicos da Sociologia. O texto do manual efetivamente dispensa o uso dos clássicos, na medida em que resume para o aluno (e, é claro, também para o professor) o que foi produzido por Durkheim, Marx e Weber18. Esse traço do manual didático, que na proposta comeniana representava a perspectiva de barateamento da atividade de ensino, visto que dispensaria tanto a erudição do professor como tornaria mais acessível o conhecimento assim veiculado (produziria um livro mais econômico) já está presente na obra de Fernando de Azevedo. Completa-se, no entanto, quando a universalização da escola torna o manual didático condição sine qua non para sua efetivação.

Daí que o manual proposto por Meksenas, compactado em suas 149 páginas, também dispense a leitura dos clássicos para sua utilização. Mesmo as recomendações de leituras complementares, ao longo das quatro unidades temáticas que o compõe, não faz menção a essas obras. Uma vez que o autor defende a importância da teorização como elemento central para que o educando possa realizar a leitura crítica da sociedade, torna-se contraditória sua defesa em torno da relevância da teoria, quando ela deve ser construída a partir dos poucos elementos teóricos presentes nos textos de apoio. Também pode ser questionado, nesse mesmo contexto, o caráter científico desse material: se não é capaz de colocar o aluno em contato com a produção científica mais relevante, de que forma poderá proporcionar as condições para que esse sujeito se torne produtor de ciência, mesmo que na condição inicial de utilizar o conhecimento adquirido para a leitura do real?

Tendo se tornado o elemento que vai direcionar o desenvolvimento do trabalho didático, o manual ganha espaço no interior da relação educativa. Em função disso as duas propostas, no plano das metodologias de ensino, embora proclamem a centralidade do professor na tarefa educativa, dedicam grande parte de seus esforços a esclarecer como melhor utilizar o manual didático. Azevedo, ainda num momento de transição, discorre de forma geral como seu texto poderia servir de guia no trabalho do professor. Já Meksenas, colocado no redemoinho do império do manual didático e cedendo a uma visão instrumental que se fortaleceu na atual etapa da sociedade capitalista, não teve como não ceder à pormenorização das tarefas a serem desenvolvidas pelo professor, tendo como base o manual didático (chegando a detalhar quantos dias e como o professor poderia proceder 
em cada aula). Aspecto interessante é que além de subordinar o trabalho do professor, ou seja, do trabalhador que o utiliza na condição de instrumento de trabalho, o manual didático, como toda mercadoria, também tenha se adequado à função de subordinar o consumidor, isto é, o aluno, reforçando dessa forma a necessidade de seu consumo. Por isso os dois manuais se prestam à tarefa de instrumentalizar professores e alunos. Assim o manual didático, como elemento central da relação educativa posta na escola moderna, vai cumprir seu papel no processo de reprodução das mercadorias, principalmente nos setores produtivos relacionados ao fazer escolar (ARRUDA \& SILVEIRA, 2003).

\section{Considerações finais}

À guisa de conclusão, é importante destacar o caráter introdutório desse trabalho, visto que permanece como desafio, por exemplo, a análise de outros manuais de Sociologia produzidos com a finalidade de atenderem a escola média, tanto nos férteis anos 19301940, como em períodos posteriores. Nesse sentido, parece frutífera a proposta metodológica de avaliar o conteúdo e as propostas de uso dos referidos manuais.

Da mesma forma, a descrição das condições de produção desses manuais ainda permanece como um desafio para futuras investigações, visto que a institucionalização do campo de produção científica de uma dada disciplina é um elemento importante na sua transformação em disciplina escolar. Além disso, no caso da Sociologia, a partir do momento em que deixou de ser obrigatória na escola secundária, em 1941 (embora permanecesse presente no ensino normal), intelectuais como Fernandes (1980) e Candido (2006) já apontavam para o progressivo abandono, pelos profissionais da área, das reflexões concernentes ao ensino de Sociologia, fora do contexto universitário.

Um último ponto que vale destacar diz respeito ao presente momento da história da Sociologia como disciplina escolar, com o retorno de sua presença obrigatória no ensino médio. Nesse sentido, já é sentido o aumento do movimento editorial em torno da produção de material didático para o trabalho do professor em sala de aula. Como salienta Alves (2001), apesar de todos os recursos tecnológicos produzido pela sociedade capitalista em sua atual etapa de desenvolvimento, e em que pesem as dificuldades de acesso a esses materiais, não se sente qualquer arrefecimento na reprodução da mesma modalidade de material que tem marcado a escola moderna. Só que dessa feita, o mesmo vem adaptado às linguagens multimídia, à consulta pela internet e, como essas mídias estão subordinadas a uma rígida economia de tempo e espaço, a informação ganha um caráter ainda mais simplificado e objetivado. Quando não, mais uma vez citando Alves (2001), o professor as utiliza dentro das mesmas condições em que já vinha utilizando o antigo manual...

\section{Referências}

ALVES, G. L. A produção da escola pública contemporânea. Campo Grande: UFMS; Campinas: Autores Associados, 2001.

ALVES, G. L. O trabalho didático na escola moderna: formas históricas. Campinas: Autores Associados, 2005.

ARRUDA, E. E. de.; SILVEIRA, G. S. O impacto da expansão escolar no mercado de material didático-pedagógico. In: SEMINÁRIO NACIONAL DE ESTUDOS E 
PESQUISAS “HISTÓRIA, SOCIEDADE E EDUCAÇÃO NO BRASIL”, 6, 2003, Campinas. Anais... Campinas: Unicamp, 2003.

AZEVEDO, F. de. A renovação educacional e o livro. In: A educação e seus problemas. 4.ed. São Paulo: Melhoramentos, 1948. p. 197-200.

AZEVEDO, F. de. Princípios de sociologia: pequena introdução ao estudo da sociologia geral. 11.ed. São Paulo: Duas Cidades, 1973.

AZEVEDO, F. de. Sociologia educacional. 3.ed. São Paulo: Melhoramentos, 1954.

BITTENCOURT, C. M. F. (Org.). O saber histórico na sala de aula. 3.ed. São Paulo: Contexto, 1997.

BONAZZI, M.; ECO, U. Mentiras que parecem verdades. São Paulo: Summus, 1980. (Novas buscas em educação, 6).

CANDIDO, A. Sociologia: ensino e estudo. Sociologia, São Paulo, v. 11, n. 3, 1949.

CANDIDO, A. A Sociologia no Brasil. Tempo Social, São Paulo, v. 18, n. 1, p. 271-301, jun. 2006.

CARNEIRO LEÃO, A. Panorama sociológico do Brasil. Rio de Janeiro: Centro Brasileiro de Pesquisas Educacionais; Instituto Nacional de Estudos Pedagógicos, 1958.

CARVALHO, L. M. G. X. de; MATTOS, S. S. Sociólogos e sociologia: breve cronologia da história da ciência, da organização estadual e nacional e da profissionalização no Brasil. São Paulo: 1996. Disponível em:<www.sociologos.org.br>. Acesso em 13 abr. 2009.

CHACON, W. História das idéias sociológicas no Brasil. São Paulo: Grijalbo; Edusp, 1977.

COMÉNIO, J. A. Didáctica Magna: tratado da arte universal de ensinar tudo à todos. 2.ed. Lisboa: Calouste Gulbekian, 1976.

COSTA EDUARDO, O. da. O ensino dos conceitos básicos da Etnologia. Sociologia, São Paulo, v. 11, n. 3, 1949.

COSTA PINTO, L. A. Ensino da Sociologia nas escolas secundárias. Sociologia, São Paulo, v. 11, n. 3, 1949.

DEIRÓ, M. de L. C. As belas mentiras: a ideologia subjacente aos textos didáticos. 10.ed. São Paulo: Moraes, 1981.

DURKHEIM, E. As regras do método sociológico. 9.ed. São Paulo: Melhoramentos, 1978.

ERASMO. De pueris. Revista Intermeio, Campo Grande, v. 2, n. 3, 1996. Encarte especial.

FERNANDES, F. A Sociologia no Brasil: contribuição para o estudo de sua formação e desenvolvimento. 2.ed. Petrópolis: Vozes, 1980. 
FONSECA, S. G. Caminhos da História Ensinada. Campinas: Papirus, 1993.

GATTI JÚNIOR, D. A escrita escolar da História: livro didático e ensino no Brasil (1970-1990). Bauru: EDUSC; Uberlândia: EDUFU, 2004.

MACHADO, C. de S. O Ensino da Sociologia na escola secundária brasileira:

levantamento preliminar. Revista da Faculdade de Educação, São Paulo, v. 13, n. 1, p. 115-142, 1987.

MARX, K. O Capital: crítica da economia política. 5.ed. Rio de Janeiro: Civilização Brasileira, 1980. Parte 4: a produção da mais valia relativa. p. 359-579.

MEKSENAS, P. Aprendendo Sociologia: a paixão de conhecer a vida. 4.ed. São Paulo: Loyola, 1987.

MEKSENAS, P. Sociologia da Educação: uma introdução ao estudo da escola no processo de transformação social. São Paulo: Loyola, 1988.

MEKSENAS, P. Sociologia. 2.ed.rev.aum. São Paulo: Cortez, 1994. (Coleção Magistério $2^{\circ}$ grau. Série Formação Geral).

MEKSENAS, P. Sociologia: subsídios para Sociologia Geral; parte integrante do Projeto Diretrizes Gerais para o Ensino de $2^{\circ}$ grau Núcleo Comum (Convênio MEC/PUC-SP1988). Brasília: MEC, [1988?]. Mimeografado.

MEUCCI, S. A institucionalização da sociologia no Brasil: os primeiros manuais e cursos. Campinas: 2000. Dissertação (Mestrado em Sociologia) - Universidade Estadual de Campinas.

MUNAKATA, K. História que os livros didáticos contam, depois que acabou a ditadura no Brasil. IN: FREITAS, Marcos Cezar (org.). Historiografia brasileira em perspectiva. São Paulo; Contexto; Bragança Paulista: USF, 1998. p. 271-296.

PAOLI, N. J. As relações entre Ciências Sociais e educação nos anos 50 e 60 a partir das histórias e produções intelectuais de quatro personagens: Josidelth Gomes Consorte, Aparecida Joly Gouveia, Juarez Brandão Lopes e Oracy Nogueira. São Paulo: 1995. Tese (Doutorado em Educação) - USP.

PEREIRA, L. A escola numa área metropolitana: crise e racionalização de uma empresa pública de serviços. São Paulo: Edusp, 1967.

PIERSON, D. Difusão da ciência sociológica nas escolas. Sociologia, São Paulo, v. 11, n. 3, 1949.

RIOS, J. A. Contribuições para uma Didática da Sociologia. Sociologia, São Paulo, v. 11, n. 3, 1949. 
Notas:

${ }^{1}$ Visto que o ensino médio passou pelo menos por quatro reformas entre 1930 e os anos 1980 (Reforma Francisco Campos, em 1931; Reforma Capanema, em 1942; reforma introduzida pela Lei n. 5692/1971 e reforma introduzida pela Lei n. 7044/1982), optou-se por denominá-lo a partir da nomenclatura introduzida pela atual LDBEN (Lei n. 9394/1996), considerando que está se tratando sempre da fase da escolarização que antecede os umbrais do ensino superior, tenha ela caráter de formação geral (escola secundária e de $2^{\circ}$ grau), tenha ela caráter profissionalizante (no caso em questão, escola normal ou magistério).

2 Depois de 1941, e antes das reformas encetadas durante o regime militar após 1964, permaneceu como disciplina optativa no ensino secundário, enquanto a Sociologia Educacional se manteve no currículo da escola normal. Também em função desse curto período de presença da Sociologia no ensino secundário com exceção da Sociologia Educacional, na escola normal — os trabalhos produzidos sobre a disciplina na escola secundária, em anos mais recentes, ainda são poucos, por um lado (MEUCCI, 2000; MACHADO, 1987; PAOLI, 1995); muito embora, por outro, alguns textos que trataram do processo de constituição do campo sociológico no Brasil tenham perpassado questões mais gerais, pertinentes também ao ensino da disciplina (CARNEIRO LEÃO, 1958; CHACON, 1977; FERNANDES, 1980).

${ }^{3}$ Reflexão semelhante pode ser encontrada no número especial da revista Sociologia, composta por artigos de vários autores (CANDIDO, 1949; COSTA EDUARDO, 1949; COSTA PINTO, 1949; PIERSON, 1949; RIOS, 1949) que têm como foco a questão educacional.

${ }^{4} \mathrm{Na}$ grade do ensino normal, além da disciplina Sociologia da Educação ou Sociologia Educacional era prevista também a Sociologia Geral. A presente obra destina-se ao ensino dessa última disciplina.

${ }^{5}$ Pode-se levantar a hipótese, ainda a ser confirmada em estudos posteriores, que ao utilizar a nomenclatura manual científico seja preocupação do autor reafirmar dois princípios: a) diferenciar sua proposta daquela que tinha como centro o "livro de texto", “(...) que assume a função absorvente, quase despótica, de regulador de atividades, como imposição ao natural desenvolvimento do espírito infantil [ e do aluno, de maneira geral] e absoluta indiferença ante suas necessidades e interêsses" (AZEVEDO, 1948, p. 197); b) a importância da ciência de referência, a Sociologia, como fonte das reflexões presentes no manual, mesmo que esse último não objetive a formação profissional do sociólogo.

${ }^{6}$ Por isso cada capítulo apresenta, no seu final, a seção Problemas e discussões, que visa introduzir questionamentos que levem o aluno e o professor a utilizar os conteúdos introduzidos em cada unidade.

7 Sobre o trabalho de campo, Meucci cita alguns exemplos de pesquisas sugeridas pelos manuais de Sociologia produzidos para a escola secundária, entre os anos 1930 e 1940. Cf. MEUCCI, 2000.

${ }^{8}$ Visto que o autor compartilha a posição durkheiminiana de que é possível, ao estudioso dos fatos sociais, ser imparcial em suas análises sobre esses mesmos fatos, desde que munido do aparato metodológico adequado para a observação e explicação de seu objeto, ele estende esse posicionamento para o trabalho de exposição dos resultados da experiência sociológica, objetivo de sua obra. Cf. DURKHEIM, 1978.

${ }^{9} \mathrm{O}$ que significa, a rigor, a continuidade dos estudos iniciados pelo próprio Durkheim.

${ }^{10}$ Entre os acontecimentos significativos para a mobilização em torno do ensino de Sociologia é importante lembrar o I Congresso Nacional de Sociólogos, realizado na cidade de Belo Horizonte, entre os dias 22 e 26 de fevereiro de 1979, cuja temática foi "Sociedade e Sociologia no Brasil"; a apresentação do primeiro Projeto de Lei em São Paulo, reintroduzindo o ensino de Sociologia em todas as escolas de segundo graus (PL n. 343, de 27 de junho de 1979, de autoria do deputado estadual Mauro Bragato (PMDB)); a aprovação, pelo Congresso Nacional, da Lei n. 7.044/82, que alterou parcialmente a Lei n. 5.692/71, flexibilizando a obrigatoriedade da profissionalização no segundo grau e abrindo a possibilidade para serem introduzidas disciplinas optativas, como a Sociologia, na parte denominada "diversificada" do currículo do ensino de segundo grau (CARVALHO \& MATTOS, 1996).

${ }^{11}$ Uma primeira versão do trabalho de Meksenas foi publicada, ainda datilografada, pelo próprio MEC, em 1988 (MEKSENAS, 1988). Já no ano seguinte, 1989, e em colaboração com a Editora Cortez, foi produzida a Coleção Magistério - $2^{\circ}$ grau, reunindo 11 volumes na série dedicada à formação geral (Matemática, Física, Química, Biologia, Língua Portuguesa e Literatura Brasileira, História, Geografia, Filosofia, Sociologia (MEKSENAS, 1994), Arte na Educação Escolar e Língua Inglesa), complementados pelos 12 livros da série dedicada às disciplinas específicas de formação do professor (Didática, Filosofia da Educação, História da Educação, Psicologia da Educação, Metodologia do Ensino de História e Geografia, Sociologia 
da Educação, Metodologia do Ensino de Matemática, Metodologia do Ensino de Educação Física, Alfabetização e Leitura, Metodologia do Ensino de Ciências, Estrutura e Funcionamento do Ensino de $1^{\circ}$ Grau e Metodologia do Ensino de Arte). Para as análises realizadas nesse texto será utilizada essa última versão, frente ao caráter mais orgânico e sistemático que a mesma assume.

12 Os coordenadores do projeto, pela PUC-SP, foram os professores Selma Garrido Pimenta e José Carlos Libâneo.

${ }^{13}$ Grande parte dos textos apresentados para o estudo das unidades pertence ao próprio Meksenas.

${ }^{14}$ Sobre essa etapa de produção do manual didático no Brasil cf. GATTI, 2004.

${ }^{15} \mathrm{Cf}$., a respeito dessa fase da história da produção capitalista na qual predomina a produção manufatureira, Marx, 1980, p. 359 et seq.

16 “A cada classe sejam destinados livros de texto próprios, que contenham todo o programa prescrito para essa classe (quanto à instrução, à moral e à piedade), para que, durante o espaço de tempo em que os jovens são conduzidos pelo caminho destes estudos, não tenham necessidade de nenhum outro livro, e com a ajuda destes livros possam ser conduzidos infalìvelmente às metas fixadas" (COMÉNIO, 1976, p. 430).

17 Apesar disso, Munakata (1998) alerta para as possíveis interpretações conspiracionistas em torno dos manuais didáticos. Analisando um trabalho como "As Belas Mentiras", de Deiró (1981), o autor aponta que não existe neutralidade científica e que aqueles que são considerados "progressistas" ou "neutros" também cometem erros conceituais e podem fazer também o "jogo do inimigo". Considera-se aqui que, de fato, se deve partir do pressuposto de que o problema não está somente na ideologia e sim na limitação desse instrumento, que se coloca única fonte, como portador de todo o conhecimento, impedindo o acesso às demais fontes.

${ }^{18}$ Interessante notar que Fernando de Azevedo, ao combater a centralidade do "livro de texto" - no seu entender um traço da escola tradicional que deveria ser combatido pelo escolanovismo - reconhece igualmente a oportunidade que se abriria aos alunos na medida em que se lhes oportunizasse o contato com outras obras, visando despertar “(...) o 'espírito crítico', pelas oportunidades de comparação, alarga[ndo]-se [com elas] o campo de suas leituras e, com elas, o horizonte mental e social dos alunos." (AZEVEDO, 1948, p. 198). Ora, tal iniciativa caberia a um professor ou coletivo de professores cujo conhecimento e erudição o manual didático veio substituir, visto a desnecessidade do mesmo na escola comeniana. Também é importante destacar que a preocupação dos escolanovistas em colocar no centro da relação educativa o aluno não se sustenta, uma vez que o manual didático se impõem como elemento central dessa relação.

Artigo recebido em: 20/03/2010

Aprovado para publicação em: 16/06/2010 